\title{
The Effects of Chloride and Sulphate Ions on the Electrochemical Behaviour of Tin in Aqueous Solutions
}

\author{
B. Ait Addi ${ }^{a, b}$, E. Ait Addi ${ }^{a, *}$ and M. Hamdani ${ }^{b}$ \\ ${ }^{a}$ Equipe de recherche Génie des Procédés et Ingénierie Chimique, Ecole Supérieure de \\ Technologie d'Agadir, B.P: 33/S, Agadir, Maroc \\ ${ }^{b}$ Laboratoire Electrochimie, Photocatalyse et Environnement, Faculté des Sciences, Agadir, \\ B.P. 28/S, Agadir, Maroc
}

Received December 31, 2016; accepted March 30, 2017

\begin{abstract}
The corrosion behaviour of pure tin in an aqueous solution simultaneously containing $\mathrm{Cl}^{-}$and $\mathrm{SO}_{4}{ }^{2-}$ ions has been studied using electrochemical techniques, optical and scanning electron microscopy. Measurements were conducted under different chloride and sulphate ions concentrations. The potentiodynamic polarisation curves showed that the pitting potential, $\mathrm{E}_{\mathrm{pit}}$, is independent from the variation of $\mathrm{pH}$, temperature and chloride and sulphate concentration of the solution. In its turn, an increase of these parameters stimulates shifting of corrosion potential to more active values and leads to an increase of the corrosion and passive current densities. The electrochemical features were strongly supported by optical and scanning electron micrographs of the corroded surfaces of the pure tin samples after potentiodynamic polarisation experiments and immersion tests.
\end{abstract}

Keywords: corrosion, tin, passivation, chloride, sulphate and potentiodynamic polarisation curves.

\section{Introduction}

Tin is a moderately corrosion resistant material, consequently, it is very widely used in industry, especially as a protective coating material for iron in contact with aggressive solutions [1]. The corrosion behaviour of tin in alkaline media [2-7], carboxylic, and the so-called fruit acids [8-12], has attracted the attention of many researchers. There are numerous studies on the corrosion effect of chloride and sulphate ions, and, in most studies, test solutions were prepared using these anions and ions of interest. Ait Addi et al. [13] suggested that the corrosiveness of industrial water depends on the ratio of the concentration of $\mathrm{Cl}^{-}$ and $\mathrm{SO}_{4}{ }^{2-}$ to $\mathrm{HCO}_{3}{ }^{-}$, where $\mathrm{Cl}^{-}$and $\mathrm{SO}_{4}{ }^{2-}$ ions are aggressive ions, whereas $\mathrm{HCO}_{3}{ }^{-}$ions have inhibitive properties. The anodic behaviour and corrosion of

\footnotetext{
*Corresponding author. E-mail address: e.aitaddi@uiz.ac.ma
} 
pure tin has been studied using electrochemical techniques under different experimental conditions. Referring to its studies, in most cases, the anodic polarization of tin exhibits an active/passive transition. There is a general agreement that tin secondary passivation is due to the precipitation of a thin film of $\mathrm{Sn}(\mathrm{OH})_{4}$ which undergoes dehydration to yield a more stable film of $\mathrm{SnO}_{2}$ on the metal surface [7]. On the other hand, the passivation breaks down when the surface is exposed to corrosive solutions that contain aggressive anions, such as halides, sulphate, and others [13-16].

The objective of this work is to study the corrosion behaviour of pure tin in an aqueous solution simultaneously containing $\mathrm{Cl}^{-}$and $\mathrm{SO}_{4}{ }^{2-}$ ions, using electrochemical techniques, optical and scanning electron microscopy. The effect of the $\mathrm{pH}$, temperature, and chloride and sulphate concentrations on the corrosion of pure tin will also be examined. So far, no literature that investigates the corrosion behaviour of pure tin in solutions which simultaneously contain $\mathrm{Cl}^{-}$and $\mathrm{SO}_{4}{ }^{2-}$ ions has been published.

\section{Experimental}

Electrochemical measurements were carried out in a conventional cylindrical three-electrode tempered glass cell. The working electrode was made of pure tin rod (Aldrich 99.99\%) axially embedded in "Araldite" holders to obtain an exposed circular area of $0.785 \mathrm{~cm}^{2}$. A saturated calomel electrode (SCE) and a platinum electrode were used as the reference and auxiliary electrodes, respectively. Prior to each experiment, the surface of the working electrode was mechanically polished with different grade emery papers until 1200 grade, degreased with acetone, and quickly rinsed with bidistilled water. The electrochemical study was carried out using a potentiostat/galvanostat PGZ 100, which was controlled by a computer using the Volta-Master software. Potentiodynamic polarisation curves were recorded at a scan rate of $60 \mathrm{mV} / \mathrm{min}$. Prior to electrochemical measurements, the working electrode was maintained at free potential for 30 minutes. Polarization resistance, $\mathrm{Rp}$, is defined as the slope of the polarization curve at $E_{\text {corr. }} \pm 10 \mathrm{mV} / \mathrm{SCE}$. The morphology and composition of the tin surface were studied using both optical and scanning electron microscopy, and energy dispersive X-ray.

Experiments were carried out in an aqueous solution containing $0.01 \mathrm{M} \mathrm{Cl}^{-}$and $0.008 \mathrm{M} \mathrm{SO}_{4}{ }^{2-}$. All aqueous solutions were prepared using bidistilled water and analytical grade chemicals (p.a Merck) and they were deaerated by bubbling $\mathrm{N}_{2}$ through the cell, unless otherwise stated. Thereafter, a constant flow of $\mathrm{N}_{2}$ was maintained through the experiments. All experiments were repeated three times to ensure reproducibility, at $20^{\circ} \mathrm{C}$.

\section{Results and discussion}

\section{Effect of chloride and sulphate ions concentrations}

Fig. 1 represents the polarization curves of a tin electrode in a $0.01 \mathrm{M} \mathrm{NaCl}$ aqueous solution containing various concentrations of $\mathrm{SO}_{4}{ }^{2}$, ranging from 0.008 
M to $1 \mathrm{M}$. Fig. 2 shows the polarization data of sodium chloride concentrations on the potentiodynamic polarization curves of pure tin in $0.08 \mathrm{M}$ solutions of sulphate concentrations. The corresponding electrochemical parameters deduced from these curves are given in Table 1. It was observed that the cathodic branch showed a linear portion which was characteristic of the reduction of water, according to a mechanism of pure activation [17]. The examination of the anodic branch permits to conclude that tin undergoes a passivation phenomenon with rupture of passivity.

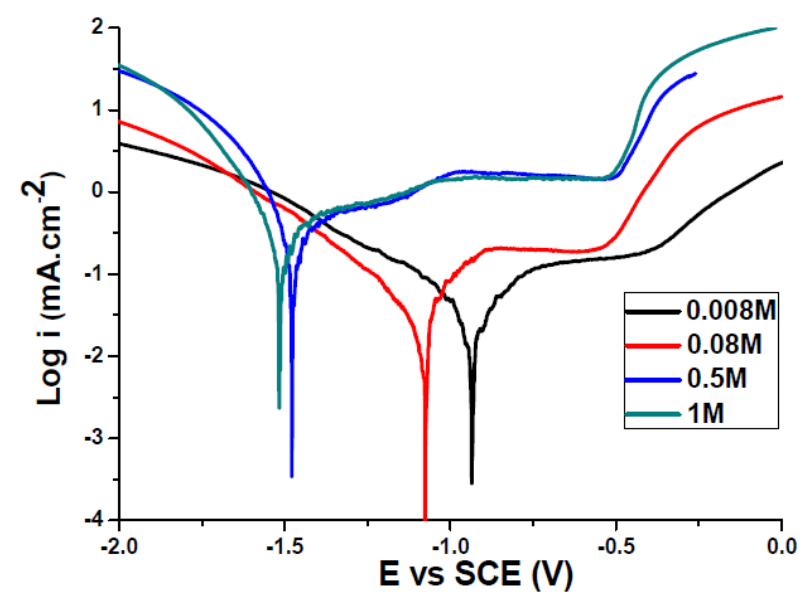

Figure 1. Polarization curves of pure tin in a $0.01 \mathrm{M} \mathrm{NaCl}$ solution containing various concentrations of $\mathrm{Na}_{2} \mathrm{SO}_{4}$ at $20{ }^{\circ} \mathrm{C}$ and at a scan rate of $60 \mathrm{mV} \mathrm{m}{ }^{-1}$.

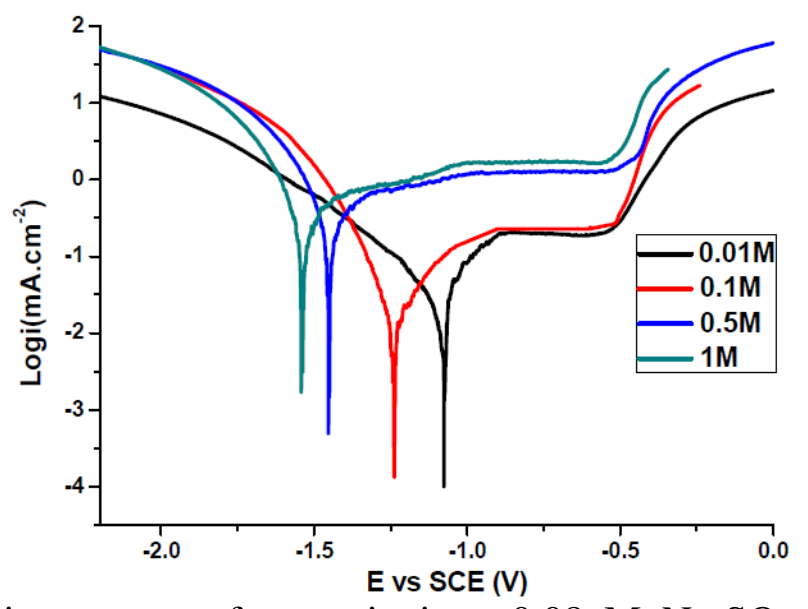

Figure 2. Polarization curves of pure tin in a $0.08 \mathrm{M} \mathrm{Na}_{2} \mathrm{SO}_{4}$ solution containing various concentrations of $\mathrm{NaCl}$ at $20^{\circ} \mathrm{C}$ and at a scan rate of $60 \mathrm{mV} \mathrm{m}{ }^{-1}$.

Indeed, the anode current density increases with the electrode potential to reach a current plateau called passivation plateau. The formation of the passive layer could be related to the presence of tin oxide/hydroxide that partially passivates the metallic surface, as confirmed by some authors [18-21]. The passive current density remains almost constant (passive region), and then abruptly increases at a certain critical pitting potential $\left(\mathrm{E}_{\mathrm{pit}}\right)$, where the passive current suddenly rises, indicating initiation and growth of pitting attack, and denoting film breakdown. According to some authors $[22,23]$, the formation of the passive layer in the neutral medium could be described by the following scheme: 


$$
\begin{gathered}
\mathrm{Sn}+2 \mathrm{OH}^{-} \rightarrow \mathrm{Sn}(\mathrm{OH})_{2}+2 \mathrm{e}^{-} \\
\mathrm{Sn}(\mathrm{OH})_{2} \rightarrow \mathrm{SnO}+\mathrm{H}_{2} \mathrm{O} \\
\mathrm{SnO}+\mathrm{H}_{2} \mathrm{O}+2 \mathrm{OH}^{-} \rightarrow \mathrm{Sn}(\mathrm{OH})_{4}+2 \mathrm{e}^{-} \\
\mathrm{Sn}(\mathrm{OH})_{4} \rightarrow \mathrm{SnO}_{2}+2 \mathrm{H}_{2} \mathrm{O}
\end{gathered}
$$

Inspections of data reveal that both uniform and localized corrosion are affected by adding increasing amounts of chloride and sulphate ions. The first action results in the deterioration of the general corrosion resistance of the material. The obtained results indicate that an increase on the concentration of these anions gradually heightens the corrosion current densit, $\mathrm{I}_{\text {corr }}$, and passive current density, $\mathrm{I}_{\mathrm{pass}}$, and decreases the polarisation resistance value, $\mathrm{Rp}$.

Table 1. Corrosion parameters obtained from Tafel extrapolation curves for pure tin at different concentrations at $20^{\circ} \mathrm{C}$.

\begin{tabular}{ccccccc}
\hline & $\begin{array}{c}\mathbf{c} \\
(\mathrm{M})\end{array}$ & $\begin{array}{c}\mathbf{E}_{\text {corr. }} \\
(\mathrm{mV} \text { vs. SCE })\end{array}$ & $\begin{array}{c}\mathbf{E}_{\text {pit. }} \\
(\mathrm{mV} \text { vs. SCE })\end{array}$ & $\begin{array}{c}\mathbf{I}_{\text {corr. }} \\
\left(\mu \mathrm{A} . \mathrm{cm}^{-2}\right)\end{array}$ & $\begin{array}{c}\mathbf{I}_{\text {pass. }} \\
\left(\mu \mathrm{A} . \mathrm{cm}^{-2}\right)\end{array}$ & $\begin{array}{c}\text { Rp } \\
\left(\Omega . \mathrm{cm}^{-2}\right)\end{array}$ \\
\hline \multirow{4}{*}{$\begin{array}{c}\text { Chloride } \\
\text { concentration }\end{array}$} & 0.01 & -1074 & -568 & 27 & 192 & 605 \\
\cline { 2 - 7 } & 0.1 & -1297 & -555 & 57 & 238 & 163 \\
\cline { 2 - 7 } & 0.5 & -1452 & -518 & 263 & 1273 & 39 \\
\hline \multirow{3}{*}{$\begin{array}{c}\text { Sulphate } \\
\text { concentration }\end{array}$} & 0.008 & -1533 & -526 & 400 & 1646 & 24 \\
\cline { 2 - 7 } & 0.08 & -1074 & -568 & 12 & 27 & 1075 \\
\cline { 2 - 7 } & 0.5 & -1471 & -487 & 230 & 125 & 605 \\
\hline
\end{tabular}

Moreover, it can be observed that increasing the amount of added chloride and sulphate ions, at all concentrations, makes the current density higher at the passive state, and shifts the corrosion potential, $\mathrm{E}_{\text {corr., }}$ to more active values from $848 \mathrm{mV}$ to $-1533 \mathrm{mV}$, without change in the pitting potential; and it also enlarges the width of the passive region below the pitting potential, $\mathrm{E}_{\mathrm{pit}}$. This effect could be attributed to the direct participation of the dissolution processes and to the formation of soluble complexes [24], as well as to the adsorption of these anions on the surface, forming potentially active dissolution sites. The aggressiveness of these ions as pitting agents may be attributed [25] to their competitive adsorption with the passivating species, as $\mathrm{OH}^{-}$and $\mathrm{H}_{2} \mathrm{O}$, on the surface of the passive film. This indicates activation in the anodic dissolution of the oxide film, and it clearly means that uniform thinning of the initial oxide through the chemical dissolution by the hydroxide ion attack dominates over the pitting corrosion by the chloride and sulphate ions attack. 


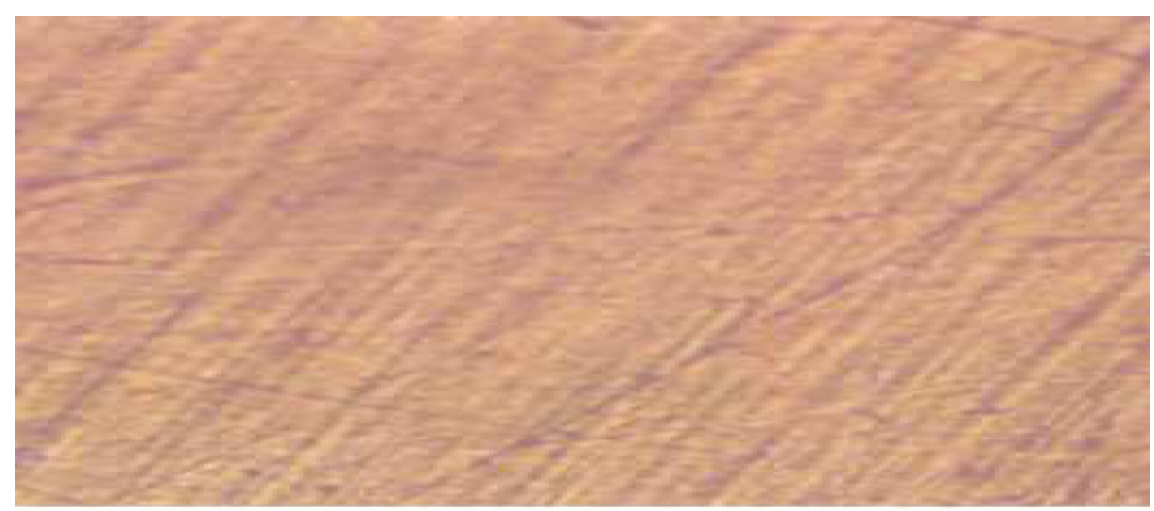

Figure 3. Optical micrograph of pure tin before immersion in the synthetic medium.

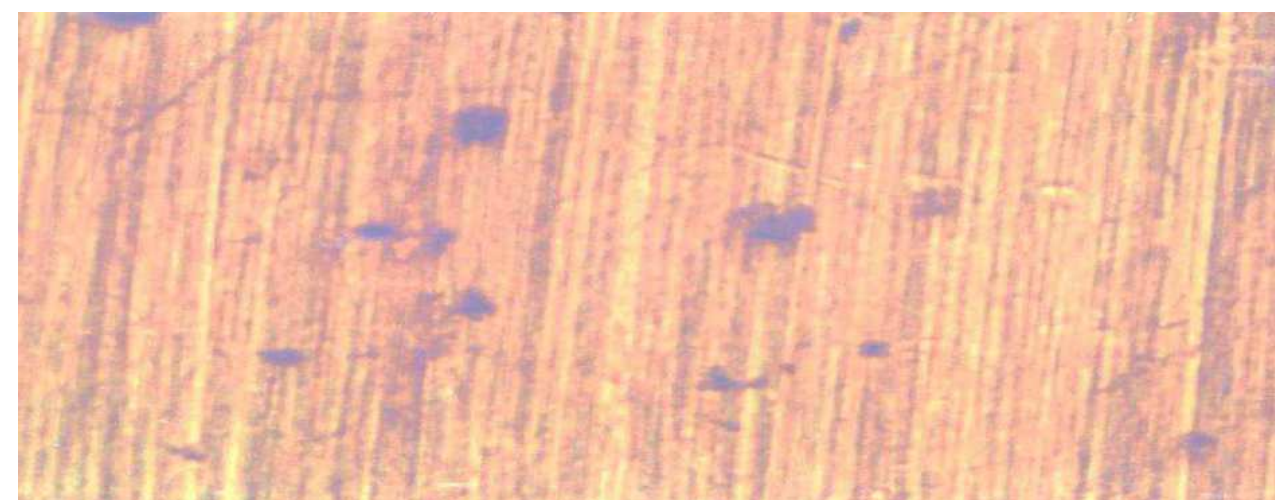

Figure 4. Optical micrograph of pure tin after 24 hours immersion in a solution consisting of $0.01 \mathrm{M} \mathrm{NaCl}$ and $0.08 \mathrm{M} \mathrm{Na}_{2} \mathrm{SO}_{4}$ (x10).

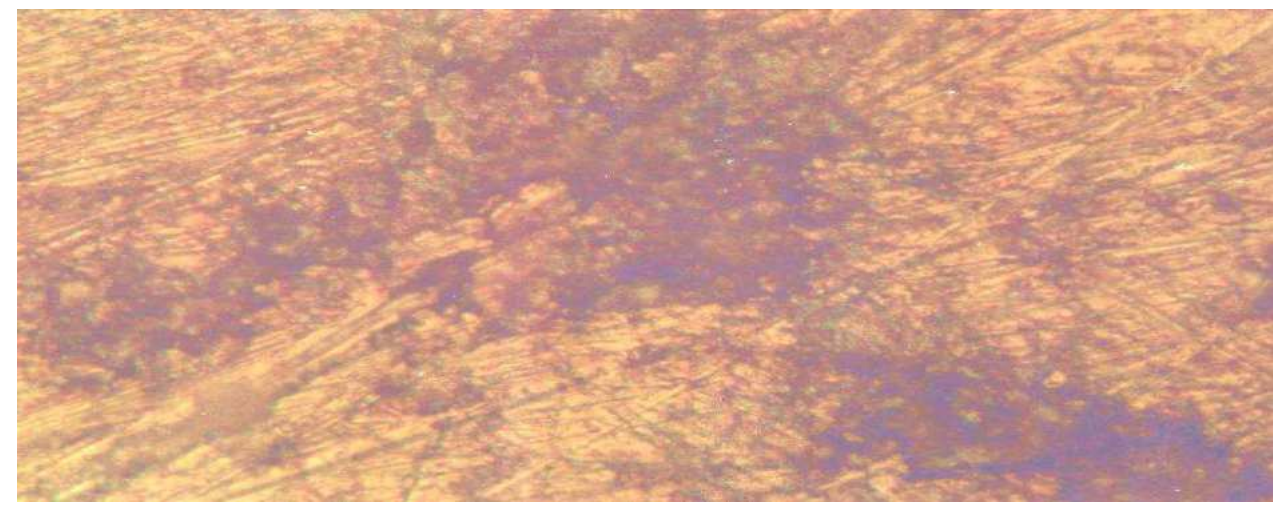

Figure 5. Optical micrograph of pure tin after 24 hours immersion in a solution consisting of $0.01 \mathrm{M} \mathrm{NaCl}$ and $0.08 \mathrm{M} \mathrm{Na}_{2} \mathrm{SO}_{4}(\mathrm{x} 40)$.

Figs. 3, 4 and 5 show the optical micrograph of the surface of the sample before and after 24 hours immersion in $0.01 \mathrm{M} \mathrm{NaCl}, 0.08 \mathrm{M} \mathrm{Na}_{2} \mathrm{SO}_{4}$ solutions. These micrographs clearly show the damage caused by this aggressive solution. As a consequence of this attack, an oxide film is formed on the surface of the sample, and hemispherical pits with different size are grown throughout the surface of the sample.

As it can be observed from Figs. 6, 7 and 8, the SEM micrographs of the surfaces of tin before and after the potentiodynamic polarisation in a solution consisting of 
$0.01 \mathrm{M} \mathrm{NaCl}$ and $0.08 \mathrm{M} \mathrm{Na}_{2} \mathrm{SO}_{4}$ showed a novel morphology of the attack, which is considerably different from that produced by immersion experiments.

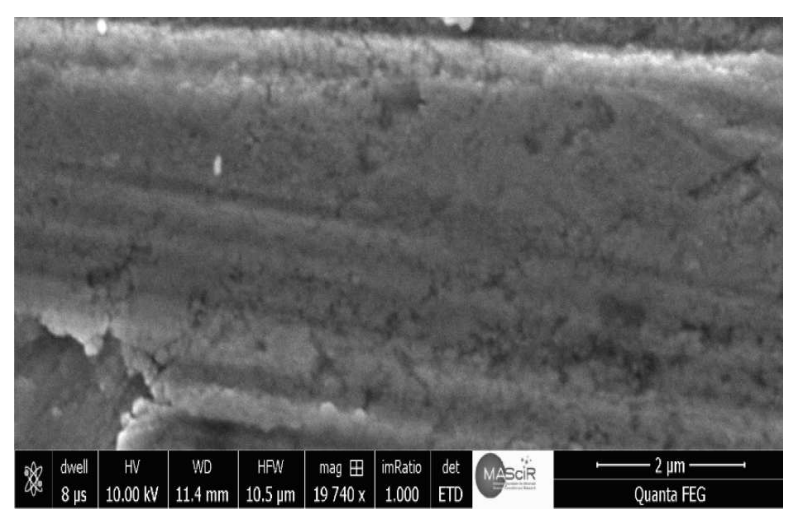

Figure 6. SEM micrograph of polished pure tin surface before potentiodynamic polarisation.

The treatment of the pure tin samples using potentiodynamic anodic polarisation leads to the formation of crystallographic pitting. The presence of some of geometric facets could be explained by the fact that the attack probably occurs following a well-defined crystallographic direction [26].

Experiments revealed that pure tin undergoes two types of localised corrosion processes, leading to the formation of hemispherical and crystallographic pitting. Hemispherical pitting is found to occur on the surface of this material under a simple exposure in a corrosive solution, whereas for the formation of the crystallographic pits, it is necessary to polarise the metal.

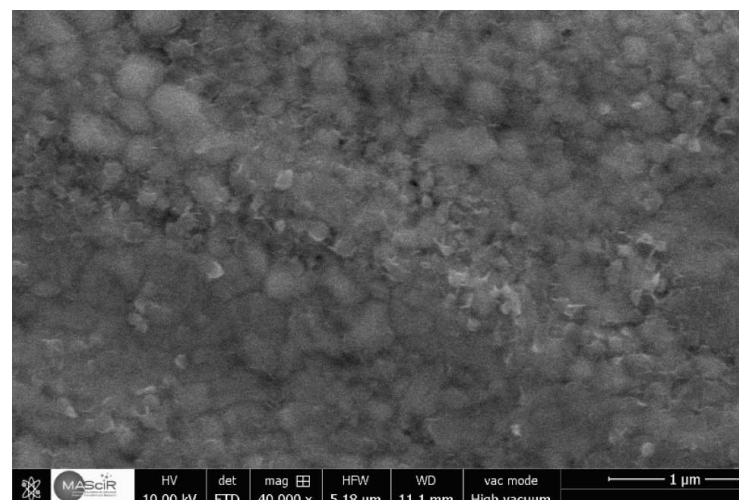

Figure 7. SEM micrograph of pure tin after the potentiodynamic polarisation from $2000 \mathrm{mV}$ to $-650 \mathrm{mV}$ (passive region) in a solution consisting of $0.01 \mathrm{M} \mathrm{NaCl}$ and 0.08 $\mathrm{M} \mathrm{Na}_{2} \mathrm{SO}_{4}$. 


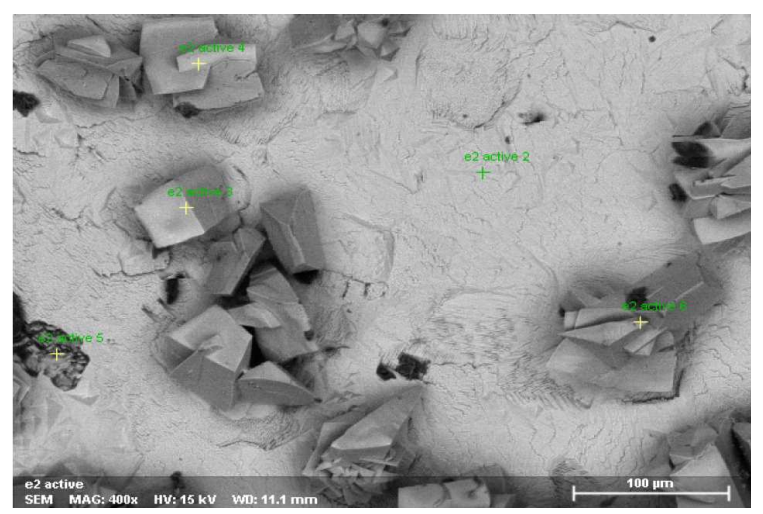

Figure 8. SEM micrograph of pure tin after potentiodynamic polarisation from -2000 $\mathrm{mV}$ to $+2000 \mathrm{mV}$ in a solution consisting of $0.01 \mathrm{M} \mathrm{NaCl}$ and $0.08 \mathrm{M} \mathrm{Na}_{2} \mathrm{SO}_{4}$.

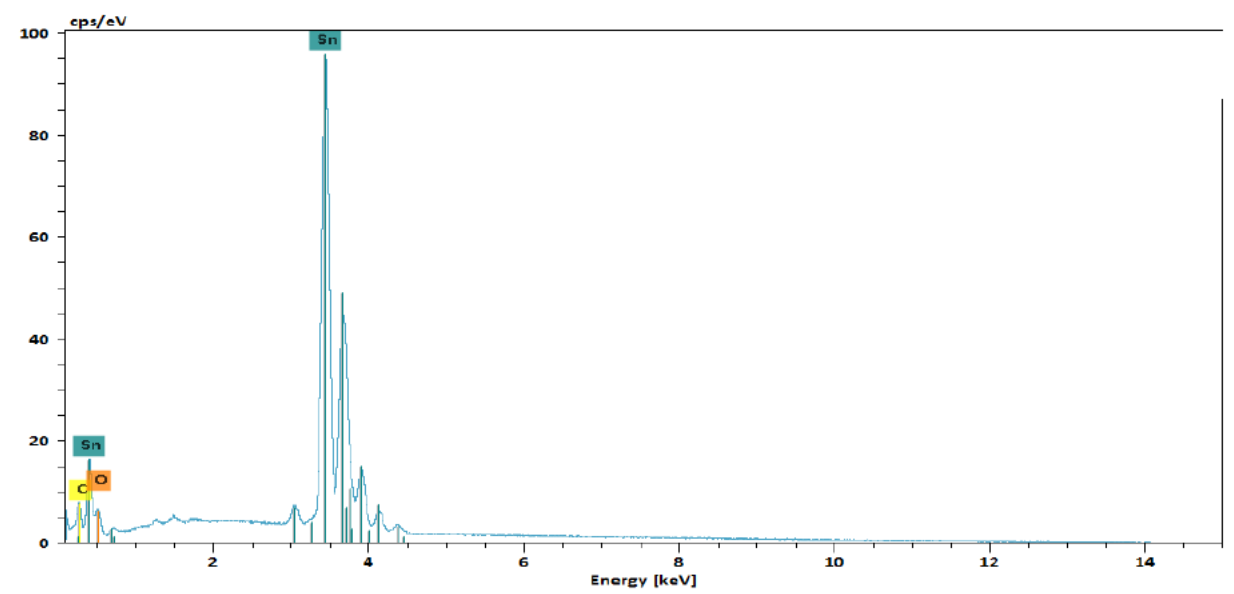

Figure 9. EDS spectrum of pure tin surface after potentiodynamic polarisation from $2000 \mathrm{mV}$ to $-650 \mathrm{mV}$ ( passive region) in a solution consisting of $0.01 \mathrm{M} \mathrm{NaCl}$ and $0.08 \mathrm{M} \mathrm{Na}_{2} \mathrm{SO}_{4}$.

The chemical composition of the sample surface was examined by energy dispersive X-ray. The examination of the spectrum presented in Fig. 9 shows the presence of peaks related to tin and oxygen. The reported ratio of peak intensity varies with the nature of the analysed surface area. In the case of an analysis made on the corrosion product, recorded spectra (Fig. 10) showed additional lines characteristic of the existence of $\mathrm{S}$. In addition, the $\mathrm{O}$ signal is enhanced (due to the oxygen atoms present in the $\mathrm{SO}_{4}{ }^{2-}$ ions). It could be concluded that the oxide film formed in these solutions contains a certain amount of incorporated sulphur, presumably as sulphate anions. This indicates a deep penetration and incorporation of $\mathrm{SO}_{4}{ }^{2-}$ ions into the bulk of the passive oxide film. 


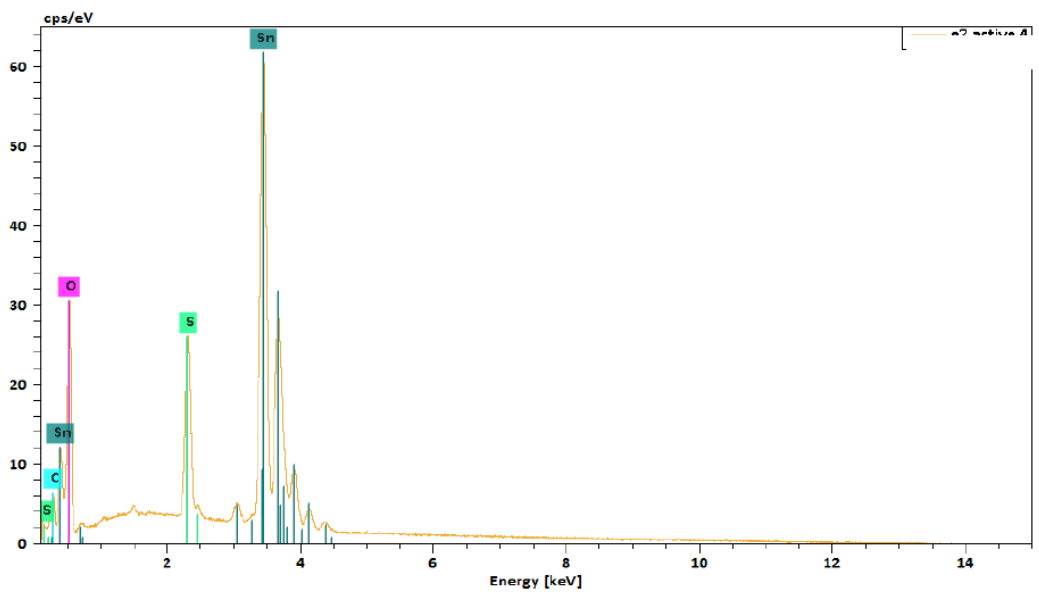

Figure 10. EDS spectrum of pure tin surface after potentiodynamic polarisation from $-2000 \mathrm{mV}$ to $+2000 \mathrm{mV}$ in a solution consisting of $0.01 \mathrm{M} \mathrm{NaCl}$ and $0.08 \mathrm{M} \mathrm{Na}_{2} \mathrm{SO}_{4}$.

As it can be observed, the increase of the ions concentration has a pronounced effect on the corrosion current and, consequently, on the dissolution rate. This behaviour is illustrated in Fig. 11 for both anions. As the results indicate, the log $\mathrm{i}_{\text {corr. }}$ and $\log \mathrm{c}_{\text {ions }}$ relations are both linear over the studied concentration range, according to the following equation:

$$
\log \mathrm{i}_{\text {corr. }}=\mathrm{a}+\mathrm{n} \log \mathrm{c}
$$

where $i_{\text {corr. }}$ is the corrosion rate, $c$ is the molar concentration of ions, $a$ is the value of $\log i_{\text {corr. }}$ at $c=1 \mathrm{M}$ and $n$ is the slope of the linear plot which represents the electrochemical reaction order.

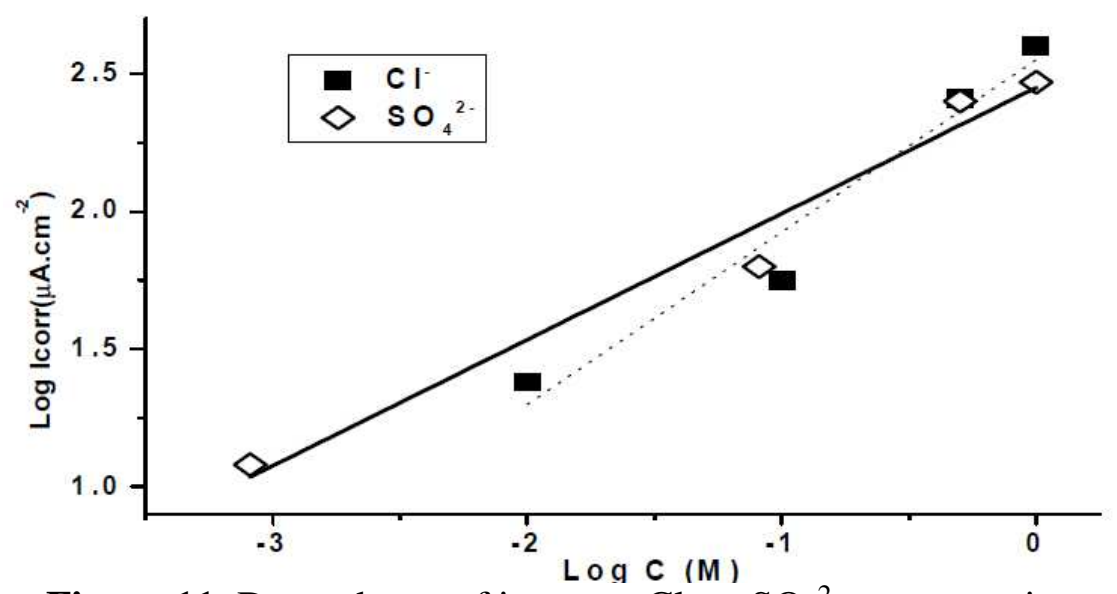

Figure 11. Dependence of icorr. on $\mathrm{Cl}^{-}$or $\mathrm{SO}_{4}{ }^{2-}$ concentrations. 


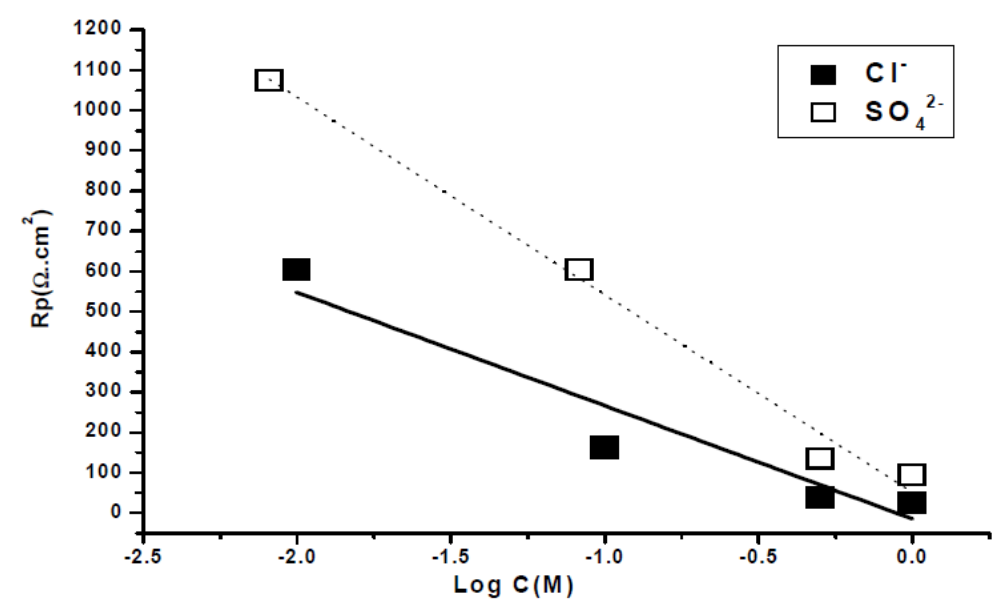

Figure 12. Dependence of $\mathrm{Rp}$ on $\mathrm{Cl}^{-}$or $\mathrm{SO}_{4}{ }^{2-}$ concentration.

From Fig. 11, the slope of the straight line for $\mathrm{Cl}^{-}$ion is observed to be $\sim 0.63$ and for $\mathrm{SO}_{4}{ }^{2-}$ ion is $\sim 0.46$, which indicates that the $\mathrm{Cl}^{-}$ion has a higher rate of dissolution than the $\mathrm{SO}_{4}{ }^{2-}$ ion, which is in good agreement with $\mathrm{Rp}$ measurements (Fig.12). Also, the positive value of the slopes is an indication that the corrosion rate is directly proportional to the aggressive ions concentration,

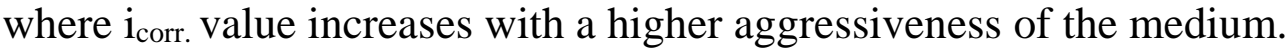

$$
\begin{array}{lll}
\log \mathrm{i}_{\text {corr. }}=0.63 \log \mathrm{C}_{\mathrm{Cl}-}+2.55 & \left(\mathrm{r}^{2}=0.94\right) & \text { for } \mathrm{Cl}^{-} \\
\log \mathrm{i}_{\text {corr. }}=0.46 \log \mathrm{CSO}^{2-}+2.45 & \left(\mathrm{r}^{2}=0.96\right) & \text { for } \mathrm{SO}_{4}{ }^{2-} \\
\log \mathrm{Rp}=-0.84 \log \mathrm{C}_{\mathrm{Cl}-}+1.36 & \left(\mathrm{r}^{2}=0.98\right) & \text { for } \mathrm{Cl}^{-} \\
\log \mathrm{Rp}=-0.33 \log \mathrm{C}_{\mathrm{SO} 4}{ }^{2-}+2 & \left(\mathrm{r}^{2}=0.91\right) & \text { for } \mathrm{SO}_{4}{ }^{2-}
\end{array}
$$

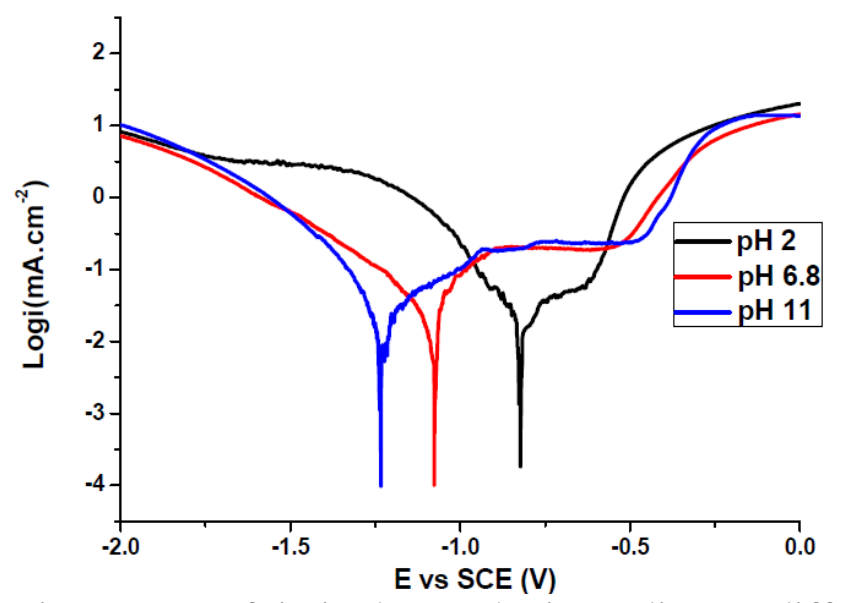

Figure 13. Polarization curves of tin in the synthetic medium at different $\mathrm{pH}$ at $20{ }^{\circ} \mathrm{C}$.

\section{Effect of pH}

Fig. 13 represents the effect of $\mathrm{pH}$ values ranging from 2 to 11 on the corrosion of pure tin in a $0.01 \mathrm{M} \mathrm{NaCl}, 0.08 \mathrm{M} \mathrm{Na}_{2} \mathrm{SO}_{4}$ solution at $20{ }^{\circ} \mathrm{C}$. The fitting results obtained from potentiodynamic polarization curves are listed in Table 2. The data display that: 
- the potentiodynamic curves are strongly $\mathrm{pH}$ dependent;

- the corrosion potentials shift in the active direction as acidity decreases due to active dissolution;

- the corrosion rates (reflected by $i_{\text {corr. }}$ and $R_{p}$ ) do not differ significantly;

- the passive current densities ( $i_{\text {pass. }}$ ) increase linearly with a higher $\mathrm{pH}$.

At $\mathrm{pH} 2$, pure tin shows a very narrow passive range, and localized film breakdown occurs at a relatively low anodic potential $(-629 \mathrm{mV})$, whereas at $\mathrm{pH}$ 5 and $\mathrm{pH} 11$, it exhibits significant passivity.

Table 2. Electrochemical parameters obtained from potentiodynamic polarization curves in Fig.11.

\begin{tabular}{cccccc}
\hline $\mathbf{p H}$ & $\begin{array}{c}\mathbf{E}_{\text {corr. }} \\
(\mathrm{mV} \text { vs. SCE })\end{array}$ & $\begin{array}{c}\mathbf{E}_{\text {pit. }} \\
(\mathrm{mV} \text { vs. SCE })\end{array}$ & $\begin{array}{c}\mathbf{I}_{\text {corr. }} \\
\left(\mu \mathrm{A} \mathrm{cm}^{-2}\right)\end{array}$ & $\begin{array}{c}\mathbf{I}_{\text {pass. }} \\
\left(\mu \mathrm{A} \mathrm{cm}^{-2}\right)\end{array}$ & $\begin{array}{c}\mathbf{R p} \\
\left(\Omega \mathrm{cm}^{-2}\right)\end{array}$ \\
\hline 2 & -822 & -629 & 28 & 54 & 230 \\
\hline 6.8 & -1074 & -568 & 27 & 192 & 605 \\
\hline 11 & -1232 & -478 & 25 & 205 & 1160 \\
\hline
\end{tabular}

\section{Effect of temperature}

The effect of increasing temperature on the potentiodynamic polarization curves of $\mathrm{Sn}$ electrodes in a $0.01 \mathrm{M} \mathrm{NaCl}, 0.08 \mathrm{M} \mathrm{Na}_{2} \mathrm{SO}_{4}$ solution was studied as shown in Fig. 14. The results display that the enhancement in temperature (from $20{ }^{\circ} \mathrm{C}$ to $60{ }^{\circ} \mathrm{C}$ ) causes a shift of the polarization curves towards a more negative direction, leading to an acceleration of the tin electrode dissolution. Furthermore, as given in Table 3, both corrosion and passive current densities linearly increase with a higher solution temperature, and the passive layer produced in the metal surface becomes fragile.

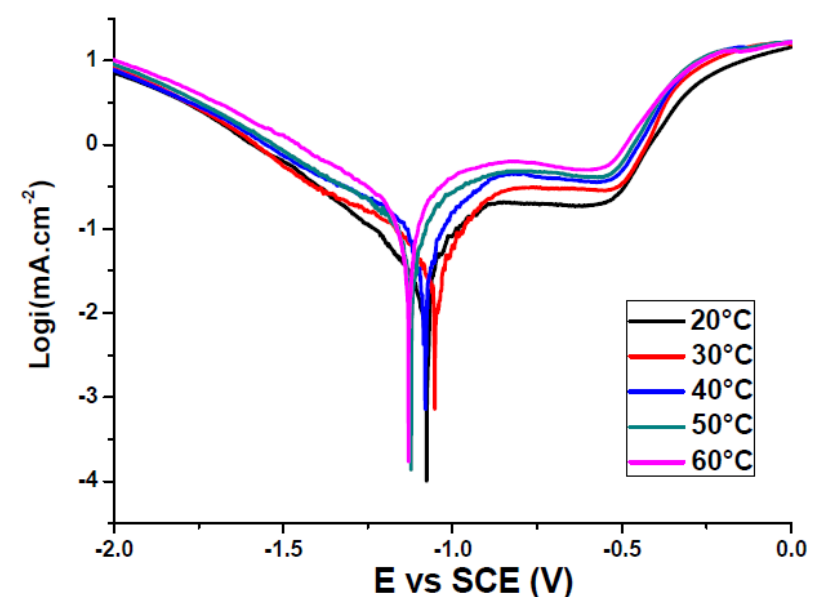

Figure 14. Polarization curves of pure tin in the synthetic medium at various temperatures.

In order to clarify the effect of temperature on the corrosion rate in the passive state, the apparent activation energies were calculated. The corrosion rate is related to temperature by the Arrhenius equation:

$$
\log \mathrm{i}_{\text {corr. }}=\log \mathrm{A}-\left(\mathrm{E}_{\mathrm{a}} / 2.303 \mathrm{RT}\right)
$$


where $i_{\text {corr. }}$ is the corrosion current density, $A$ is the pre-exponential constant, $E_{a}$ is the activation energy of the corrosion process in $\mathrm{kJ} \cdot \mathrm{mol}^{-1}, \mathrm{R}$ is the universal gas constant in $\mathrm{J} \cdot \mathrm{mol}^{-1} \cdot \mathrm{K}^{-1}$, and $\mathrm{T}$ is the absolute temperature in $\mathrm{K}$.

Table 3. Effect of temperature on electrochemical parameters of pure tin in the synthetic medium.

\begin{tabular}{cccccc}
\hline $\mathbf{T ~}\left({ }^{\circ} \mathbf{C}\right)$ & $\begin{array}{c}\mathbf{E}_{\text {corr. }} \\
(\mathrm{mV} \text { vs. SCE })\end{array}$ & $\begin{array}{c}\mathbf{E}_{\text {pit. }} \\
(\mathrm{mV} \text { vs. SCE })\end{array}$ & $\begin{array}{c}\mathbf{I}_{\text {corr. }} \\
\left(\mu \mathrm{A} . \mathrm{cm}^{-2}\right)\end{array}$ & $\begin{array}{c}\mathbf{I}_{\text {pass. }} \\
\left(\mu \mathrm{A} . \mathrm{cm}^{-2}\right)\end{array}$ & $\begin{array}{c}\text { Rp } \\
\left(\Omega . \mathrm{cm}^{-2}\right)\end{array}$ \\
\hline 20 & -1074 & -568 & 27 & 192 & 605 \\
\hline 30 & -1052 & -521 & 49 & 309 & 574 \\
\hline 40 & -1081 & -526 & 74 & 371 & 431 \\
\hline 50 & -1122 & -541 & 89 & 412 & 387 \\
\hline 60 & -1129 & -548 & 131 & 517 & 277 \\
\hline
\end{tabular}

The activation energies ( $E_{\mathrm{a}}$ and $\mathrm{E}_{\mathrm{a}}$ ) of the corrosion process are determined from the slope of $\log \left(\mathrm{i}_{\text {corr. }}\right)$ and $\log \left(\mathrm{i}_{\text {pass. }}\right)$ versus $1 / \mathrm{T}$ graph (Fig. 15). The data provided the apparent activation energy values:

$$
\begin{aligned}
\mathrm{E}_{\mathrm{a}} & =25.8 \mathrm{~kJ} \cdot \mathrm{mol}^{-1} \\
\mathrm{E}_{\mathrm{a}} & =18.6 \mathrm{~kJ} \cdot \mathrm{mol}^{-1}
\end{aligned}
$$

According to these values it is observed that the passivity of pure tin is very affected by the variation of temperature.

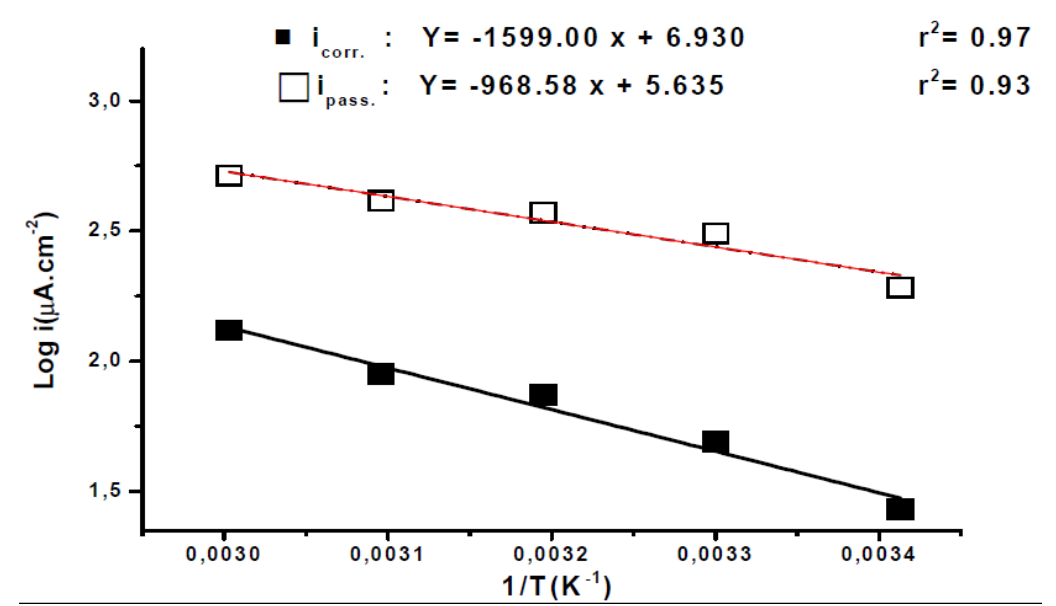

Figure 15. Arrhenius plots for $i_{\text {corr. }}$ and $i_{\text {pass. }}$ of pure tin in the synthetic medium.

\section{Conclusions}

The corrosion behaviour of pure tin was found to be dependent on the $\mathrm{pH}$, temperature and both chloride and sulphate concentration of the solution. The potentiodynamic polarisation curves showed that:

i. the pitting potential, $\mathrm{E}_{\mathrm{pit}}$, is independent of the variation of $\mathrm{pH}$, temperature and chloride and sulphate concentration of the solution;

ii. the corrosion potential shifts to more active values with an increase of these parameters; 
iii. the corrosion and passive current densities increase with higher $\mathrm{pH}$, temperature and anions concentrations, whereas the polarisation resistance linearly decreases.

The electrochemical features were strongly supported by the optical and SEM micrographs of the corroded surfaces of the pure tin samples, after potentiodynamic polarisation experiments and immersion tests.

\section{References}

1. Gannetti BF, Sumodjo PT, Rabockai T, et al. Electrochim Acta. 1992;37:143.

2. Abd El-Rehim SS, El Sayed A, El Samahi AA. Br Corros J. 1985;20:196.

3. Moina CA, Ybarra GO. J Electroanal Chem. 2001;504:175.

4. B.X. Huang, P. Tornatore, Y. Singli, Electrochim. Acta. 2001;46:671.

5. Alvatarez PE, Ribotta SB, Flolquer ME, et al. Corros Sci. 2012;44:49.

6. Alvatarez PE, Gervasi CA. Corros Sci. 2004;46:91.

7. Gervasi CA, Palacios PA, Bimbi MVF, et al. J Electroanal Chem. 2007;601:194.

8. Abd El Rehim SS, Zaky AM, Mohamed NF. J Alloys Comp. 2006;424:88.

9. Abdel Rehim SS, Sayyah SM, El Deeb MM. Mater Chem Phys. 2003;80:696.

10. Gervasi CA, Alvarez PE, Bimbi MVF, et al. J Electroanal Chem. 2007;601:194.

11. El-Sherbini EEF. J Electroanal Chem. 2005;584:167.

12. Jafarian M, Gobal F, Danaee I, et al. Electrochimica Acta. 2008;53:4528.

13. Ait Addi EH, Bazzi L, Elhilali M, et al. Appl Surf Sci. 2006;253:555.

14. Addi EA, Mihit M, Bazzi L, et al. J Mater Environ Sci. 2010;1:111.

15. Addi EA, L. Bazzi L, Hilali M. et al. Can J Chem. 2003;81:29.

16. Ekilik VV, Korsakova EA, Berezhnaya AG, et al. Int J Corros Scale Inhib. 2013;2:224.

17. Bazzi L, Kertit S, Hamdani M. J Chim Phys. 1995;92:1612.

18. Álvarez D, Collazo A, Nóvoa XR, et al. Prog Org Coat. 2014;77:2066.

19. Begum SN, Basha A, Muralidharan VS, et al. Mater Chem Phys. 2012;132:1048.

20. Zhong X, Zhang G, Qiu Y, et al. Electrochem Comm. 2013;27:63-68.

21. Nam ND, Kim MJ, Jang YW, et al. Corros Sci. 2010;52:14.

22. Drogowska M, Menard H, Brossard L. J Appl Electrochem. 1991;21:84.

23. Alvarez PE, Ribota SB, Folquer ME, et al. Corros Sci. 2002;44:49.

24. Goldstone S. Textbook of physical chemistry. 2nd ed. London: Van Nostrand; 1956. p. 945.

25. Cotton FA, Wilkinson G. Advanced inorganic chemistry. 3rd ed. London: John Wiley \& Sons; 1972. p. 475.

26. Gimenez Ph, Rameau JJ, Rebioul MC. Corrosion. 1981;37:673. 